\title{
IMPLANTAÇÃO E USO NA EDUCAÇÃO AMBIENTAL DE UM SISTEMA PARA REUTILIZAČÃO DA ÁGUA DE REFRIGERAÇÃO DE DESTILADOR
}

\author{
Bárbara Roberta Morais ${ }^{1}$ \\ Bruno Alberto Soares Oliveira ${ }^{2}$ \\ Paulinelly de Sousa Oliveira ${ }^{3}$ \\ Meryene de Carvalho Teixeira ${ }^{4}$
}

Resumo: O aumento na demanda de água, somado à degradação dos corpos hídricos, cria um cenário de escassez desse recurso. As instituições de ensino devem promover mudanças socioambientais para minimizar esse impacto. O IFMG - Campus Bambuí (MG) possui um Laboratório de Análises de Solo que utiliza alta quantidade de água destilada, com desperdício da água de resfriamento. Assim, este trabalho apresenta um sistema de reuso dessa água nas caixas d'água da biblioteca para fins não potáveis. Análises físico-químicas e microbiológica da água pós-destilador mostraram que apenas o valor de cloro residual desviou-se do padrão. Para difundir a ideia de reuso da água, realizaramse intervenções em escolas municipais por meio de maquete e protótipo do sistema.

Palavras-chave: Protótipo; Reuso; Sustentabilidade; Conscientização.

Abstract: The increase in water demand, added to the degradation of water bodies, creates a scenario of scarcity of this resource. Institutions must promote socio-environmental changes to minimize this impact. IFMG - Campus Bambuí (MG, Brazil) has a Soil Analysis Laboratory that uses a high amount of distilled water, with waste of cooling water. Thus, this work presents a system for reusing this water in the water tanks of the library for non-potable purposes. Physical-area and microbiological analysis of the post-distillation water limiter that only the residual chlorine value deviated from the standard. To spread the idea of water reuse, operations were carried out in municipal schools using a model and prototype of the system.

Keywords: Prototype; Reuse; Sustainability; Awareness.

\footnotetext{
1 Instituto Federal de Minas Gerais, campus Bambuí. E-mail: barbararobertamorais@gmail.com, Link para o Lattes: http://lattes.cnpq.br/2678439027192563

2 Instituto Federal de Minas Gerais, campus Bambuí. E-mail: brunoalbertobambui@gmail.com, Link para o Lattes: http://lattes.cnpq.br/2112685965030446

3 Instituto Federal de Minas Gerais, campus Bambuí. E-mail: paulinellyoliveira@gmail.com, Link para o Lattes: http://lattes.cnpq.br/8273272599691529

4 Instituto Federal de Minas Gerais, campus Bambuí. E-mail: meryene.carvalho@ifmg.edu.br, Link para o Lattes: http://lattes.cnpq.br/7723769254941523
} 


\section{Introdução}

O grande aumento na demanda de água, causado pelo crescimento populacional $\mathrm{e}$, por consequência, 0 aumento das atividades produtivas necessárias, como industriais e do campo, somados à degradação crescente dos corpos hídricos, desmatamentos, falta de tratamento de esgoto e desperdícios, criam um cenário de escassez deste recurso cada vez mais evidente, ocasionando um colapso na biodiversidade global e afetando consideravelmente os recursos naturais (PALHARES; PEZZOPANE, 2015).

Algumas melhorias em programas e políticas públicas nacionais e internacionais relacionadas ao meio ambiente ocorreram nos últimos 30 anos. Folegatti et al. (2017) apontam uma maior atenção da administração pública em relação à sustentabilidade ambiental, levando em consideração a parte social e econômica e um novo conjunto de políticas, como a Lei de Gestão de Recursos Hídricos (9.433/1997) e a criação da Agência Nacional de Águas (ANA), ressaltando a importância desse recurso. Em 2002, o Comitê de Direitos Econômicos, Sociais e Culturais das Nações Unidas, por meio do Comentário Geral № 15, dispôs que o direito humano à água é indispensável para uma vida com dignidade, prevenindo a fome e as doenças, contribuindo para a manutenção de outros direitos humanos (OHCHR, 2002).

A importância dos recursos hídricos perpassa as últimas décadas. $A$ história revela que, em geral, os homens se estabeleceram onde a água era abundante para utilizarem em sistemas de irrigação e para sua sobrevivência. A importância da água vai além e extrapola o entendimento restrito de sentido utilitarista, pois valores simbólicos, religiosos, culturais e místicos sempre fizeram parte da cultura de muitos povos (BRUNI, 1993; DICTORO; HANAI, 2017). Porém, embora a água seja um recurso crítico e essencial para o funcionamento adequado dos sistemas biológicos, ou seja, primordial para a vida, somente com a falta dela é que muitas pessoas percebem seu valor, como ocorreu na crise hídrica nos anos de 2014/2015, quando muitas pessoas perceberam a importância e a necessidade da água potável, que, erroneamente, é colocada como um recurso natural inesgotável (COELHO et al., 2016).

Catástrofes ambientais, como o rompimento de barragens de mineradoras, também ressaltam a dependência que o ser vivo tem dos recursos hídricos. Neves-Silva e Heller (2020) apontam o quanto a água é essencial nas mais diversificadas esferas, perpassando pelos recursos econômicos, sociais e culturais até o direito a uma vida digna. Os autores também mostram a fragilidade das leis ambientais no Brasil, as disparidades sociais e a distribuição desigual dos riscos ambientais, ocasionando injustiça ambiental.

Em epidemias e pandemias, como nosso cenário atual de pandemia causada pela COVID-19, dentre os protocolos da Organização Mundial da Saúde, torna-se indispensável que todos lavem as mãos com água e sabão. Porém, segundo o Sistema Nacional de Informações sobre Saneamento (SNIS,

revista brasileira educação ambiental 
2019), mais de $16 \%$ da população brasileira não têm acesso ao abastecimento de água. Mendes, Lhamas e Maia (2020) trazem a importante reflexão da necessidade de um processo educativo ambiental que permita aos indivíduos compreenderem a crise socioambiental como instrumento para a busca de sociedades sustentáveis, apontando a educação, enquanto objeto de formação humana, como forma de melhoria.

Em virtude desses e de outros fatores, observou-se a urgente necessidade de implantação de programas construtivos e eficientes que permitam fazer o uso racional da água com a consequente conservação dos recursos hídricos, atuando com sustentabilidade. É importante destacar que alguns dos fatores que muito contribuem para o agravamento dessa situação são o consumo humano excessivo, o desperdício e a poluição crescentes, como se a população não tivesse conhecimento sobre a escassez desse recurso.

Sob a ótica dessa vertente, de um falso desconhecimento, as Instituições de Ensino (IEs), cuja principal missão é atuar como agentes transformadores, devem intervir na conscientização sobre a importância desse equilíbrio e tratar o reuso da água como uma questão educativa, cultural e cotidiana, pois, além de estarem diretamente envolvidas com a sociedade, também fazem grande uso desses recursos (ANTUNES; GHISI, 2019; DRAHEIN; LIMA; COSTA, 2019).

Ao desenvolver e implementar preocupações ambientais em seus princípios e infraestrutura, as IEs tornam-se mais ativas na promoção de mudanças sociais em direção ao desenvolvimento sustentável. Essas preocupações ambientais são traduzidas em programas de Educação Ambiental abrangentes e transversais, destinados a capacitar e promover a conscientização não apenas para os alunos, mas também para a comunidade.

$\mathrm{Na}$ literatura, verificam-se iniciativas implantadas com sucesso por IEs, tais como conscientização em intervenções escolares, reuso da água de chuva, reuso de efluentes de aparelhos de ar-condicionado e de destiladores em laboratórios (BARBOSA; COELHO, 2016; ABREU et al., 2016; MACHADO; VESTENA; FOLMER, 2016; RODRIGUES DO NASCIMENTO; LUCENA; FREIRE, 2019).

Enfatizando os laboratórios das IEs, a água é o solvente mais utilizado em análises químicas e deve possuir pureza adequada para a obtenção de resultados precisos. O procedimento mais simples para que ela alcance esse grau de pureza é a destilação convencional. Entretanto, esse sistema possui alto consumo de água para refrigeração e condensação dos vapores d'água e obtenção da água destilada. Essa água de refrigeração é, em muitos casos, descartada, corroborando o desperdício desse recurso.

Dentre os outros laboratórios do Instituto Federal de Minas Gerais (IFMG) - Campus Bambuí, o de Análises de Solo (LAS) apresenta maior desperdício de água de refrigeração devido à frequência de análises. Além 
disso, por ser um laboratório que atende a comunidade local e regional, tornase de grande necessidade demonstrar ao público ações de cunho sustentável, tornando-se referência para a multiplicação dessas ações.

Assim, considerando-se o desperdício e a possibilidade de reutilização da água descartada pelos destiladores, este trabalho teve como objetivo implantar um sistema de reuso das águas provenientes do aparelho destilador do LAS. Como este laboratório se localiza no mesmo prédio da biblioteca, o intuito foi levar a água descartada até as caixas d'água que abastecem os dois locais. Isso apresentou-se possível porque a água utilizada nos bebedouros da biblioteca é proveniente de outra fonte, não sendo ligada às caixas d'água, sendo exclusivamente para fins não potáveis.

Além disso, essa iniciativa foi apresentada aos estudantes das escolas municipais com o intuito de disseminar a sustentabilidade, incentivar o uso consciente dos recursos hídricos e atuar como multiplicador de ideias, evidenciando a tríade ciência, tecnologia e extensão.

\section{Materiais e Métodos}

\section{Destilador e medições de vazão}

O destilador utilizado como objeto de estudo do trabalho é da marca Fabbe, modelo 106. Não foi encontrado o documento para verificar a vazão deste, tendo sido necessário realizar as medições para obter tais informações.

A vazão foi medida em 5 dias diferentes, alternando entre os períodos da manhã e da tarde. Efetuou-se a coleta da água descartada em um balde com duração de tempo variando de cinco a quinze minutos por coleta.

\section{Descrição do projeto}

Inicialmente, para melhor visualização e entendimento do funcionamento do sistema de reutilização da água desperdiçada, foi esquematizado um desenho representativo do prédio da biblioteca e do LAS contendo o sistema de reaproveitamento. O desenho foi desenvolvido em plataforma 3D por meio do programa computacional SketchUp. A partir dele, foi possível também prever a quantidade de material necessária para a implementação do projeto.

Para a coleta da água descartada, foi alocada uma caixa d'água de 1000 litros dentro de uma construção de alvenaria localizada abaixo do nível do prédio, apenas $50 \mathrm{~cm}$ acima do nível do solo, para evitar a entrada da água de chuva. Uma bomba de sucção foi utilizada para a elevação dessa água para as caixas d'água que se encontram na laje do segundo andar, sendo que, para evitar avarias com a bomba de sucção, ela foi colocada em uma bombona ao lado da caixa de coleta. 


\section{Caracterização da água de reuso}

Análises físico-químicas e microbiológica foram realizadas a fim de caracterizar a qualidade da água após passar pelo destilador. As amostras foram coletadas em triplicata na caixa d'água instalada utilizando-se frascos de vidro previamente esterilizados.

Seguindo-se o "Manual Prático de Análise de Água" (BRASIL, 2013), foram medidos $\mathrm{o} \mathrm{pH}$ e a turbidez, pelo método Nefelométrico, por meio do Turbidímetro DM - Tu, e o cloro residual, pelo método da comparação visual, utilizando-se o reagente para cloro livre - DPD.

As análises de coliformes totais/E. coli foram realizadas no Laboratório de Microbiologia do Departamento de Ciências Agrárias do IFMG - Campus Bambuí por meio da técnica do número mais provável (NMP), encontrada no livro "Manual de Métodos de Análise Microbiológica de Alimentos e Água" (SILVA et al., 2017).

\section{Intervenção nas escolas municipais}

Para essa intervenção, foi construído um protótipo automatizado da motobomba, inserido em uma maquete representativa do prédio da biblioteca e do LAS, esquematizando o projeto para apresentações nas escolas municipais Dr. "Antônio Torres" e "Dulcinéa Gomes Torres", bem como na Associação "Olga Chaves Miranda", localizadas na cidade de Bambuí - MG. As ações foram únicas em cada escola, de maneira expositiva, com explanações acerca do tema "Recursos hídricos: definição, uso e reuso", alcançando um público de cerca de 200 estudantes dos anos iniciais do ensino fundamental.

Para elaboração do protótipo, utilizaram-se um motor 12V DC, um sensor de nível, uma plataforma de prototipagem Arduino Uno, isopor, tampas de refrigerante, mangueira de aquário e potes descartáveis, dentre outros materiais.

\section{Resultados e Discussões}

É possível perceber, em estudos já realizados, que o consumo de água varia de acordo com o modelo do destilador. Rodrigues do Nascimento, Lucena e Freire (2019, p. 584-586) apresentaram um levantamento com variação de valores de vazão de água consumida de 11 a $150 \mathrm{~L}$ de efluentes para destilar $1 \mathrm{~L}$ de água.

No presente estudo, calculou-se a vazão média de $50 \mathrm{~L}$ de água para refrigerar a destilação de $1 \mathrm{~L}$. Levando-se em consideração as variações mensais de análises, gasta-se uma média de $50 \mathrm{~L} /$ dia de água destilada. Assim, cerca de $2500 \mathrm{~L}$ de água diariamente são descartados - um número elevado considerando-se que essa água é vista como própria para reuso. 
Para a implantação do projeto de reutilização dessa água, foi necessário manter a concepção arquitetônica, por ser uma instituição cinquentenária. Assim, empregou-se o seguinte desenho 3D para projetar a ideia e a quantidade de material a ser gasto para a implantação do projeto. A Figura 1a representa o prédio do LAS e a biblioteca onde foi implantada a captação da água do destilador. No local indicado pela seta, encontra-se uma caixa d'água utilizada para despejo da água de resfriamento. Na Figura 1b, é representado sucintamente o sistema de reaproveitamento de água, feito em plataforma 3D.
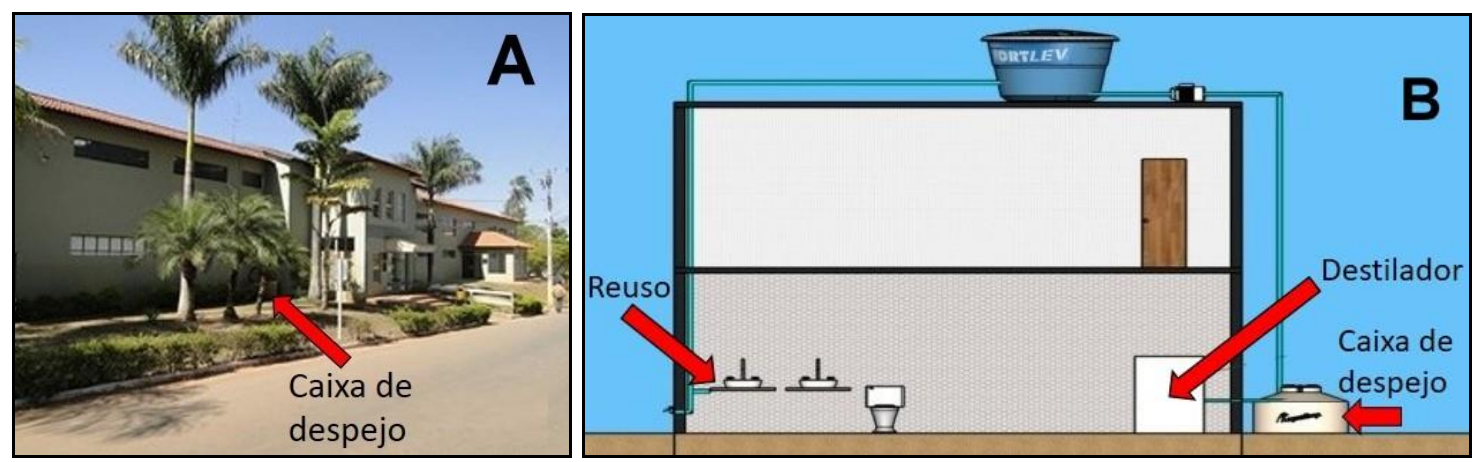

Figura 1: $a$ - LAS e Biblioteca; $b$ - Desenho em plataforma 3D.

Fonte: Os autores (2019).

A partir dessa figura, calculou-se a pressão que a bomba teria que fazer para elevar a água da caixa de coleta (chamada caixa de despejo) até uma caixa d'água, no segundo andar da biblioteca, para a distribuição para os banheiros e pias do prédio.

Levando-se em consideração a estética local do prédio, que possui localização central, a construção de alvenaria, situada abaixo do nível do prédio, foi ideal. Observou-se, após a instalação do projeto, que a estética do prédio ficou melhor, pois se retirou a caixa de despejo (Figura 2).
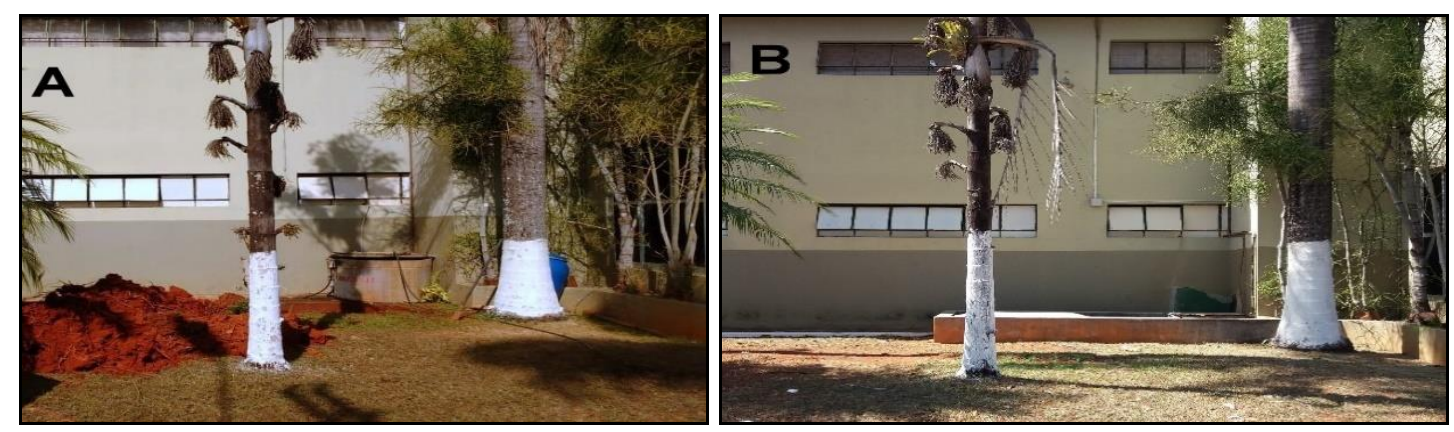

Figura 2: a - Local com a caixa de despejo no início do projeto; b - Alvenaria construída e projeto implantado.

Fonte: Os autores (2019). 
A caixa d'água, contida na Figura $2 \mathrm{a}$, era utilizada para captar a água de resfriamento do destilador, servindo apenas de depósito. Juntamente com a bombona, contendo a bomba de sucção, foram alocadas dentro da casa de alvenaria (Figura $2 b$ ), de onde sai o encanamento para abastecimento da caixa d'água, no segundo andar. Um sistema de jogo de chaves-boia foi adaptado nas caixas d'água da biblioteca para que, na ausência da água de reuso, seja acionado o abastecimento por meio da água vinda da companhia responsável pelo abastecimento no IFMG - Campus Bambuí.

Adotar fontes de reaproveitamento de água em IEs deve ser feito com grande responsabilidade, uma vez que a gestão do abastecimento requer definição de procedimentos de operação e de manutenção, além da destinação a ser atendida.

Pensando nessa responsabilidade, realizaram-se as análises de caracterização da água pós-destilação, obtendo-se valores de $\mathrm{pH}$ de 6,9, mostrando que a água se encontra dentro do padrão de potabilidade previsto pela legislação $(6,0$ a 9,5$)$. Em relação à turbidez, as amostras apresentaram os valores de 1,53 unt, atendendo ao padrão exigido pela lei, cujo limite máximo é de 5,0 unt para amostra pontual (BRASIL, 2017).

Para o cloro residual, não foi constatada grande alteração na coloração das amostras para a cor amarela, comprovando a ausência (ou irrelevante concentração) de cloro nas amostras analisadas. Devido a esse resultado, será necessário adicionar um clorador na caixa de despejo para garantir a qualidade microbiológica da água para uso.

Em todas as análises efetuadas, não houve formação de gás nos tubos de Duran. Portanto, os resultados foram negativos para a presença de coliformes totais, fecais e termotolerantes (BRASIL, 2017).

A partir dos resultados obtidos nas análises, foi possível constatar que a água pode ser utilizada para fins não potáveis, evitando, assim, o desperdício de água potável da rede de abastecimento.

Segundo Berchin et al. (2018), algumas estratégias podem ser adotadas por uma IE para iniciar a promoção da sustentabilidade: desenvolver uma Agenda Institucional; promover pesquisa na área; aprimorar o ensino do tema; aprimorar as operações do Campus Verde; estimular o alcance da comunidade; e promover a disseminação do conhecimento sobre sustentabilidade.

Assim, além do aprimoramento no ensino com a aplicação desse projeto e da colaboração no item Campus Verde, intervenções em escolas municipais foram realizadas visando multiplicar o conhecimento e disseminar a ideia de reutilização de água. O ambiente de uma intervenção entre instituições de ensino é bastante propício para aprendizagens práticas e para fazer colaborações e parcerias entre elas. 
A Figura 3 ilustra o protótipo da motobomba, instalada na maquete do LAS, e sua apresentação em uma das intervenções realizadas nas escolas municipais de Bambuí (MG).

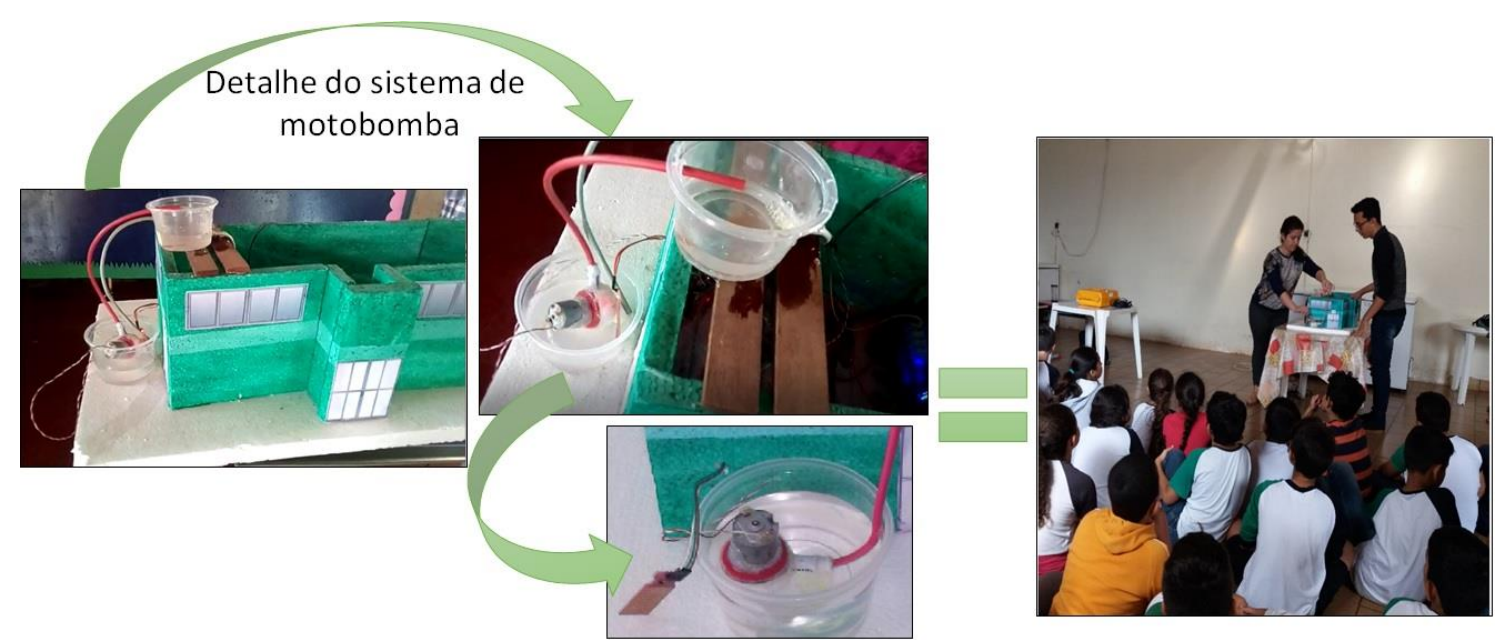

Figura 3: Esquema da motobomba instalada na maquete do LAS e intervenção realizada em uma escola municipal.

Fonte: Os autores (2019).

A maquete consiste em uma representação do prédio da biblioteca e do LAS contendo um protótipo no qual, com a caixa de despejo abastecida (pote inferior), a água é bombeada até a caixa d'água da biblioteca, mostrando a reutilização. Assim que a caixa de despejo se esvazia, a bomba desliga. Como a maquete foi desenvolvida com o uso de ferramentas de automação, como sensores e a plataforma de prototipagem Arduino, todo o mecanismo e o processo de reaproveitamento de água foram executados de maneira automática.

Dentro do tema proposto, essa intervenção conseguiu obter êxito ao conscientizar os estudantes do ensino médio em relação aos cuidados com os recursos hídricos, reaproveitamento de alguns efluentes, apresentação do tema sustentabilidade e prevenção ao mosquito Aedes aegypti e às doenças transmitidas por ele: dengue, zika e chicungunha.

Existem duas correntes principais de pensamento quando se trata do papel das IEs na sustentabilidade ambiental, podendo ambas caminhar juntas. A primeira destaca a prática da Educação Ambiental na qualificação dos alunos, e a segunda envolve a implementação de Sistemas de Gestão Ambiental no Campus, como modelos e exemplos práticos de gestão sustentável para a sociedade (TAUCHEN; BRANDLI, 2006). 


\section{Conclusões}

De acordo com as análises físico-químicas, a água encontra-se dentro dos padrões para reutilização em banheiros, lavatórios e demais ambientes que a utilizam para fins higiênicos e irrigação do jardim.

A economia com a reutilização da água descartada pelo destilador é abrangente, pois afeta tanto a parte financeira quanto a ambiental. Além dessa economia, a conscientização e a apresentação de que é possível reutilizar esse recurso vão além do esperado.

Por fim, a aproximação do IFMG - Campus Bambuí com as demais IEs do munícipio também se faz importante, e é por meio desses projetos que uma relação de contribuição é construída. As intervenções permitem uma construção mútua de saberes onde as instituições de ensino aprendem a envolver os estudantes em atividades que trabalhem a sua realidade, aprendendo a refletir sobre os problemas que afetam a sua vida, a comunidade, o país e o planeta, colocando em prática sua capacidade de ação ambiental.

Aprender a utilizar a água de forma racional e proporcionar seu reuso de maneira segura são atitudes necessárias para a preservação desse recurso e que podem ser adotadas pelos estudantes. A prática da Educação Ambiental está em gestos simples, como no aproveitamento da água da lavagem de roupas e da água da chuva para a limpeza e na reutilização da água do banho para a descarga. $O$ estudante consciente transmite essa preocupação para familiares e amigos e, de maneira indireta, pressiona órgãos públicos para a adoção de medidas ambientalmente corretas.

\section{Agradecimentos}

Ao IFMG, pelo financiamento do projeto; à FAPEMIG e ao CNPq, pela bolsa de iniciação científica; e ao IFMG - Campus Bambuí, por apoiar e permitir a execução.

\section{Referências}

ABREU, L. L. C. et al. Reutilização da água usada no processo de destilação. Rev. da Meta, v. 1, n. 1, p. 323-329, 2016.

ANTUNES, L. N.; GHISI, E. Water and energy consumption in schools: case studies in Brazil. Environment, Development and Sustainability, v. 22, p. 4225-4249, 2020.

BARBOSA, T.; COELHO, L. Sustentabilidade por meio do reuso da água dos aparelhos de ar-condicionado da faculdade de tecnologia deputado Waldyr Alceu Trigo - FATEC Sertãozinho. Rev. Academus, v. 4, n. 1, 2016.

BERCHIN, I. I. et al. The importance of international conferences on sustainable development as higher education institutions' strategies to promote sustainability: A case study in Brazil. Journal of Cleaner Production, v. 171, p. 756-772, 2018. 
BRASIL. Fundação Nacional de Saúde. Manual prático de análise de água / Fundação Nacional de Saúde - 4. ed. - Brasília: Funasa, 2013. 150 p. Disponível em: http://www.funasa.gov.br/site/wpcontent/files $\mathrm{mf} / \mathrm{manual}$ pratico de analise de agua 2.pdf. Acesso em: 05 nov. 2020.

BRASIL. Portaria de Consolidação no 5, de 28 de setembro de 2017. Anexo XX. Padrões de potabilidade da água para consumo humano. Brasília. DOU de 03/10/2017.

Disponível em: https://portalarquivos2.saude.gov.br/images/pdf/2018/marco/29/PRC-5-

Portaria-de-Consolida----o-n---5--de-28-de-setembro-de-2017.pdf Acesso em: 11 nov. 2020.

BRUNI, J. C. A água e a vida. Tempo Social. Rev. Sociol. USP, S. Paulo, v. 5, n. 1-2, p. 53-65, 1993 (editado em nov. 1994).

COELHO, C. A. S. et al. The 2014 southeast Brazil austral summer drought: regional scale mechanisms and teleconnections. Clim. Dynamics, v. 46, p. 3737-3752, 2016.

DICTORO, V. P.; HANAI, F. Y. Simbolismos da água: valores, saberes e tradições dos moradores de Pirapora - MG nas margens do rio São Francisco. Rev. Gest. Sust. Ambient., Florianópolis, v. 6, n. 1, p. 487 -503, abr./set. 2017.

DRAHEIN, A. D.; LIMA, E. P. DE; COSTA, S. E. G. da. Sustainability assessment of the service operations at seven higher education institutions in Brazil. J. of Cleaner Production, v. 212, p. 527-536, 2019.

FOLEGATTI M.V. et al. (2017) Management of Water Resources and Irrigated Agriculture in Brazil. In: BICUDO, C. E. M.; TUNDISI, J. G.; SCHEUENSTUHL, M. C. B. (eds) Waters of Brazil. Springer, Cham. Diponível em: https://link.springer.com/chapter/10.1007/978-3-319-41372-3 1. Acesso em: 15 nov. 2020.

MACHADO, G. E.; VESTENA, N. P.; FOLMER, I. (Re)uso da água da chuva: experiência no Colégio Politécnico de Santa Maria (RS). Revista Brasileira. de Educação Ambiental, v. 11, n. 5, p. 10-18, 2016.

MENDES, C. B.; LHAMAS, A. P. B.; MAIA, J. S.S. Aspectos da Educação Ambiental crítica: reflexões sobre as desigualdades na pandemia da COVID19. Revista Brasileira. de Educação Ambiental, v. 15, n. 4, p. 361-379, 2020.

NEVES-SILVA, P.; HELLER, L. Rompimento da barragem em Brumadinho e o acesso à água das comunidades atingidas: um caso de direitos humanos. Cienc. Cult., v. 72, n. 2, p.47-50, 2020.

OFFICE of the High Commissioner for Human Rights - OHCHR. General Comment No. 15: The Right to Water (Arts. 11 and 12 of the Covenant). OHCHR. 2002. 
PALHARES, J. C. P.; PEZZOPANE, J. R. M. Water footprint accounting and scarcity indicators of conventional and organic dairy production systems. J. of Cleaner Produc., v. 93, p. 299-307, 2015.

RODRIGUES DO NASCIMENTO, F. G.; LUCENA, C. M. L.; FREIRE, L. L. Reuso em laboratórios de análises ambientais: desperdícios e custos da água residual de destiladores. R. Gest. Sust. Ambient., Florianópolis, v. 8, n. 2, p.578-594, abr/jun. 2019.

SILVA, N. et al. Manual de Métodos de Análise Microbiológica de Alimentos e Água. 5aㅡ ed. Editora Blucher, 2017. 535 p.

SNIS. Sistema Nacional de Informações sobre Saneamento Básico. Diagnóstico dos serviços de Água e Esgoto, 2019. Disponível em: http://www.snis.gov.br/diagnostico-anual-agua-e-esgotos/diagnostico-dosservicos-de-agua-e-esgotos-2018. Acesso em: 15 dez. 2020.

TAUCHEN, J.; BRANDLI, L. L. A gestão ambiental em instituições de ensino superior: modelo para implantação em campus universitário. Ver. Gestão e Produção, v.13, n. 3, p. 503-515, 2006. 